\title{
Basic Edge Dominating Functions of Quadratic Residue Cayley Graphs
}

\author{
S. Jeelani Begum \\ Assistant Professor \\ Department of Mathematics, \\ MITS, Madanapalle, AP, \\ INDIA.
}

\author{
B. Maheswari \\ Professor, \\ Department of Mathematics, \\ Sri Padmavati Women's University, \\ Tirupati, AP, INDIA.
}

\begin{abstract}
Graph Theory has been realized as one of the most useful branches of Mathematics of recent origin, finding widest applications in all most all branches of sciences, social sciences, and engineering and computer science. Nathanson[8] was the pioneer in introducing the concepts of NumberTheory, particularly, the "Theory of congruences" $i$ $\mathrm{n}$ Graph Theory, thus paving way for the emergence of a new class of graphs, namely, "Arithmetic Graphs". Cayley graphs are another class of graphs associated with the elements of a group. If this group is associated with some arithmetic function then the Cayley graph becomes an arithmetic graph. Quadratic residue is an arithmetic function which is defined by: Let $\mathrm{p}$ be an odd prime and $n$, a positive integer such that $n \neq 0(\bmod p)$. If the quadratic congruence, $x^{2} \equiv n(\bmod p)$ has a solution then, $\mathrm{n}$ is called a quadratic residue mod $\mathrm{p}$. The Quadratic Residue Cayley graph $\mathrm{G}\left(\mathrm{Z}_{\mathrm{p}}, \mathrm{Q}\right)$, is the Cayley graph associated with the quadratic residue function. The theory of basic edge dominating functions in Quadratic Residue Cayley Graphs is useful in the selection of modes, those are require to focus on the development of some connected systems like market management, operating system, banking , infrastructure system etc.
\end{abstract}

\section{Keywords}

Quadratic Residue Cayley Graph, Edge Domination, Edge Dominating Functions, Basic Edge Dominating Functions.

\section{INTRODUCTION}

The concept of edge domination is introduced by Mitchell and Hedetniemi [7]. Further results on edge domination are given in Arumugam and Velammal [2]. Functional generalization for vertex subsets has been studied extensively in literature 4, 5]. Cockayne and Mynhardt [3] have introduced that edge subsets may also be embedded into sets of functions and an analogous concept of convexity could also be developed. In this paper we determine minimum edge cover, minimum edge dominating set of $G\left(Z_{p}, Q\right)$. Here we introduced the concept of basic minimal edge dominating function and derived some results.

\section{EDGE DOMINATION}

Edge Cover: An edge cover of a graph $\mathrm{G}(\mathrm{V}, \mathrm{E})$ is a set of edges which contains all the vertices of G. A minimum edge cover is one with minimum cardinality.
Edge Covering Number: The number of edges in a minimum edge cover of $\mathrm{G}$ is called the edge covering number of $\mathrm{G}$ and it is denoted by $\beta^{\prime}(G)$.

Edge Dominating Set: Let $G(V, E)$ be a graph. A subset $F$ of $\mathrm{E}$ is called an edge dominating set (EDS) if each edge in $\mathrm{E}-\mathrm{F}$ is adjacent to atleast one edge in $\mathrm{F}$.

Edge Domination Number: The minimum cardinality among all edge dominating sets of $\mathrm{G}$ is called an edge domination number of $\mathrm{G}$, and is denoted by $\gamma^{\prime}(\mathrm{G})$.

Theorem 2.1: The minimum edge cover of $G\left(Z_{p}, Q\right)$ is given by $\{(0,1),(2,3), \ldots \ldots \ldots \ldots(\mathrm{p}-3, \mathrm{p}-2),(\mathrm{p}-1,0)\}$.

Proof : Consider $G\left(Z_{p}, Q\right)$, where $p$ is an odd prime which may be of the form $4 m+3$ or $4 m+1$ for $m=0,1,2, \ldots \ldots$

Consider the set $\mathrm{F}$ of ordered pairs of vertices given by

$\mathrm{F}=\{(0,1),(2,3), \ldots \ldots \ldots,(\mathrm{p}-3, \mathrm{p}-2),(\mathrm{p}-1,0)\}$.

Since $(2 \mathrm{i}+1)-(2 \mathrm{i})=1 \in \mathrm{S}$, each ordered pair $(2 \mathrm{i}, 2 \mathrm{i}+1)$, $0 \leq \mathrm{i} \leq \frac{(\mathrm{p}-1)}{2}$ in $\mathrm{F}$ is an edge of $\mathrm{G}\left(\mathrm{Z}_{\mathrm{p}}, Q\right)$, so that $\mathrm{F}$ is a subset of $E$ in $G\left(Z_{p}, Q\right)$. Further the edges in $F$ contains all the vertices of $G\left(Z_{p}, Q\right)$, so that $F$ forms an edge cover of $\mathrm{G}\left(Z_{\mathrm{p}}, Q\right)$. To show that $\mathrm{F}$ is a minimum edge cover of $\mathrm{G}\left(\mathrm{Z}_{\mathrm{p}}\right.$, Q). Let us consider the edge set $\mathrm{F}-\left\{\mathrm{e}_{\mathrm{i}}\right\}$, where $e_{i}=(2 i, 2 i+1) \in F$, for any $i=0,1,2, \ldots, \frac{(p-1)}{2}$.

Consider the vertices $2 \mathrm{i}$ and $2 \mathrm{i}+1$. The vertex $2 \mathrm{i}$ is incident with the edge $(2 \mathrm{i}-1,2 \mathrm{i})$ and $(2 \mathrm{i}, 2 \mathrm{i}+1)$. But the edge (2i-1, $2 \mathrm{i}) \notin \mathrm{F}$ and the edge $(2 \mathrm{i}, 2 \mathrm{i}+1)=\mathrm{e}_{\mathrm{i}} \notin \mathrm{F}-\left\{\mathrm{e}_{\mathrm{i}}\right\}$. Similar is the case with the vertex $2 i+1$. That is the vertices $2 i$ and $2 i+1$ are not covered by the edges in $\mathrm{F}-\left\{\mathrm{e}_{\mathrm{i}}\right\}$. Thus $\mathrm{F}$ is a minimum edge cover of $\mathrm{G}\left(\mathrm{Z}_{\mathrm{p}}, \mathrm{Q}\right)$. Since the $(\mathrm{p}+1)$ vertices $0,1,2, \ldots \ldots . . \mathrm{p}-1,0$ can be paired into $\frac{(\mathrm{p}-1)}{2}$ distinct pairs of vertices $(2 i, 2 i+1), 0 \leq i \leq \frac{(p-1)}{2}$, it follows that the cardinality of $F$ is $\frac{(p-1)}{2}$.

The following Corollary is immediate from the above Theorem. 
Corollary 2.2: The edge covering number of $G\left(Z_{p}, Q\right)$ is $\frac{(\mathrm{p}-1)}{2}$. i.e., $\beta^{1}\left(\mathrm{G}\left(\mathrm{Z}_{\mathrm{p}}, \mathrm{Q}\right)\right)=\frac{(\mathrm{p}-1)}{2}$.

Theorem 2.3: The set of edges $\{(1,2),(3,4), \ldots,(\mathrm{p}-2, \mathrm{p}-1)\}$ in $G\left(Z_{p}, Q\right)$ form a minimum edge dominating set of $\mathrm{G}\left(\mathrm{Z}_{\mathrm{p}}, \mathrm{Q}\right)$.

Proof : Consider $\mathrm{G}\left(\mathrm{Z}_{\mathrm{p}}, \mathrm{Q}\right)$. Let $\mathrm{F}=\{(1,2),(3,4), . .,(\mathrm{p}-2, \mathrm{p}-1)\}$. Since $(2 \mathrm{i})-(2 \mathrm{i}-1)=1 \in \mathrm{S}$, each ordered pair $(2 \mathrm{i}-1,2 \mathrm{i})$, $0 \leq \mathrm{i} \leq \frac{(\mathrm{p}-1)}{2}$, in $\mathrm{F}$ is an edge of $\mathrm{G}\left(\mathrm{Z}_{\mathrm{p}}, Q\right)$, it follows that $\mathrm{F}$ is a subset of $\mathrm{E}$ in $\mathrm{G}\left(\mathrm{Z}_{\mathrm{p}}, \mathrm{Q}\right)$. Let $(\mathrm{s}, \mathrm{t}) \in \mathrm{E}-\mathrm{F}$, where $\mathrm{s} \geq 0$ and $t \neq s+1$. Consider the edge $(s, s+1)$ in $E$, where $s \neq 2 i$, $\mathrm{i}=1,2, \ldots . \frac{(\mathrm{p}-1)}{2}$. This edge belongs to $\mathrm{F}$, since $s+1-s=1 \in S$. Obviously this edge is adjacent to $(s, t)$. Since this edge is arbitrary it follows that $\mathrm{F}$ is an edge dominating set of $\mathrm{G}\left(\mathrm{Z}_{\mathrm{p}}, \mathrm{Q}\right)$.

We now show that $\mathrm{F}$ is a minimum edge dominating set of $\mathrm{G}\left(\mathrm{Z}_{\mathrm{p}}, \mathrm{Q}\right)$. Delete an edge e $=(1,2)$ from $\mathrm{F}$. Then there is an edge $(0,1) \in \mathrm{E}$ such that it is not adjacent to any edge of $\mathrm{F}$ $-\{\mathrm{e}\}$. This can be seen as follows.

The edge $(0,1)$ is adjacent to the edges $(1,2),(0, \mathrm{p}-1)$ for $\mathrm{p}>1$ as $1 \in \mathrm{S}$. Also it is adjacent to the edges $(0, q),(1, r)$, where $1<\mathrm{q}<(\mathrm{p}-1), 2<\mathrm{r}<\mathrm{p}$.

And $|0-q|=k_{1},|1-r|=k_{2}$, where $\mathrm{k}_{1}>1, \mathrm{k}_{2}>1 \in \mathrm{S}$.

But none of these edges belong to $\mathrm{F}-\{\mathrm{e}\}$, as the edges in $\mathrm{F}$ are of the form $(2 i-1,2 i)$, where $i=1,2, \ldots \ldots \frac{(p-1)}{2}$.

That is $F-\{e\}$ is not an edge dominating set of $G\left(Z_{p}, Q\right)$. Hence $F$ is a minimum edge dominating set of $G\left(Z_{p}, Q\right)$.

Corollary 2.4: The edge domination number $\gamma^{\prime}\left(G\left(Z_{p}, Q\right)\right)$ is $\frac{(\mathrm{p}-1)}{2}$.

Proof : By the above Theorem, the minimum edge dominating set of $G\left(Z_{p}, Q\right)$ is

$$
F=\{(1,2),(3,4), \ldots \ldots \ldots .,(p-2, p-1)\} . \text { Since the }(p-1)
$$

vertices $1,2,3, \ldots . \mathrm{p}-2, \mathrm{p}-1$ can be paired into $\frac{(\mathrm{p}-1)}{2}$ distinct pairs of vertices $(2 i-1,2 i), 0<i \leq \frac{(p-1)}{2}$,

it follows that the cardinality of $\mathrm{F}$ is $\frac{(\mathrm{p}-1)}{2}$.

\section{BASIC EDGE DOMINATING FUNCTIONS}

Minimal Edge Dominating Set : Let G(V, E) be a graph.

An edge dominating set (EDS) $F$ is called a minimal edge dominating set (MEDS) if no proper subset of $F$ is an edge dominating set of $\mathrm{G}$.
Edge Dominating Function : Let $\mathrm{G}(\mathrm{V}, \mathrm{E})$ be a graph. A function $f: E \rightarrow[0,1]$ is called an edge dominating function (EDF) if $\sum_{e^{\prime} \in N[e]} f\left(e^{\prime}\right) \geq 1$ for all $e \in E(G)$, where $\mathrm{N}[\mathrm{e}]$ is the closed neighbourhood of the edge e.

Minimal Edge Dominating Function : An EDF $f$ is called a minimal edge dominating function (MEDF), if for all functions $g: E \rightarrow[0,1]$ with $g<f$, g is not an edge dominating function.

Boundary Set \& Positive Set of $\mathbf{f}$ : Let $f$ be any EDF of G. The boundary set $B_{f}^{\prime}$ and the positive set $P_{f}^{\prime}$ of $f$ are defined by

$$
B_{f}^{\prime}=\left\{e \in E: \sum_{e^{\prime} \in N[e]} f\left(e^{\prime}\right)=1\right\}
$$

and

$$
P_{f}^{\prime}=\{e \in E: f(e)>0\} .
$$

Basic Minimal Edge Dominating Function : A MEDF $f$ of a graph $\mathrm{G}(\mathrm{V}, \mathrm{E})$ is called a basic minimal edge dominating function (BMEDF) if $\mathrm{f}$ can not be expressed as a proper convex combination of two distinct MEDFs.

We need the following result referred from Arumugam and Sitara Jerry [1].

Theorem 3.1: An EDF $f$ is a MEDF of $\mathrm{G}$ if and only if $B_{f}^{\prime} \rightarrow P_{f}^{\prime}$

\section{MAIN RESULTS}

Theorem 4.1: Let $f_{1}$ and $f_{2}$ be two MEDFs of $\mathrm{G}\left(\mathrm{Z}_{\mathrm{p}}, \mathrm{Q}\right)$ with $P_{f_{1}}^{\prime}=P_{f_{2}}^{\prime}$ and $B_{f_{1}}^{\prime}=B_{f_{2}}^{\prime}$. Then for e $\in E$ the following conditions hold in $\mathrm{G}\left(\mathrm{Z}_{\mathrm{p}}, \mathrm{Q}\right)$.

(i) $f_{1}(e)=1$ if and only if $f_{2}(e)=1$.

(ii) $f_{1}(e)=0$ if and only if $f_{2}(e)=0$.

(iii) $\sum_{e^{\prime} \in N[e]} f_{1}\left(e^{\prime}\right)=1$ if and only if $\sum_{e^{\prime} \in N[e]} f_{2}\left(e^{\prime}\right)=1$.

Proof: Let $f_{1}$ and $f_{2}$ be two MEDFs of $\mathrm{G}\left(\mathrm{Z}_{\mathrm{p}}\right.$, Q) with $P_{f_{1}}^{\prime}=P_{f_{2}}^{\prime}$ and $B_{f_{1}}^{\prime}=B_{f_{2}}^{\prime}$.

(i) Suppose $f_{1}(e)=1$. i.e., $f_{1}(e)>0$.

Then $e \in P_{f_{1}}^{\prime}$, as $f_{1}$ is a MEDF of $\mathrm{G}\left(\mathrm{Z}_{\mathrm{p}}, \mathrm{Q}\right)$.

By Theorem 3.1, an EDF $f$ is a MEDF of $\mathrm{G}$ if and only if $B_{f}^{\prime} \rightarrow P_{f}^{\prime}$. Thus we have $B_{f_{1}}^{\prime} \rightarrow P_{f_{1}}^{\prime}$. Then there exists an edge $e_{1} \in B_{f_{1}}^{\prime}$ such that $e_{1}$ is adjacent to e. 
Since $e_{1} \in B_{f_{1}}^{\prime}$, we have $\sum_{e^{\prime} \in N\left[e_{1}\right]} f_{1}\left(e^{\prime}\right)=1$.

That is $f_{1}(e)+\sum_{e^{\prime} \in N\left[e_{1}\right]-\{e\}} f_{1}\left(e^{\prime}\right)=1$.

Since $f_{1}(e)=1$, it follows that

$f_{1}\left(e^{\prime}\right)=0$ for all $e^{\prime} \in N\left[e_{1}\right]-\{e\}$.

By the hypothesis, we have $B_{f_{1}}^{\prime}=B_{f_{2}}^{\prime}$. Since $e_{1} \in B_{f_{1}}^{\prime}$,

it follows that $e_{1} \in B_{f_{2}}^{\prime}$.

Then $\sum_{e^{\prime} \in N\left[e_{1}\right]} f_{2}\left(e^{\prime}\right)=f_{2}(e)+\sum_{e^{\prime} \in N\left[e_{1}\right]-\{e\}} f_{2}\left(e^{\prime}\right)=1$.

If $f_{2}(e)<1$, there exists an edge $e_{2}$ in $N\left[e_{1}\right]-\{e\}$

such that $f_{2}\left(e_{2}\right)>0$.

This implies that $e_{2} \in P_{f_{2}}^{\prime}$. By the hypothesis we have $P_{f_{1}}^{\prime}=P_{f_{2}}^{\prime}$. Since $e_{2} \in P_{f_{2}}^{\prime}$, it follows that $e_{2} \in P_{f_{1}}^{\prime}$ so that $f_{1}\left(e_{2}\right)>0$. This is a contradiction to the fact that $f_{1}(e)=1$. Thus $f_{2}(e)=1$.

Therefore if $f_{1}(e)=1$ then $f_{2}(e)=1$ in $\mathrm{G}\left(\mathrm{Z}_{\mathrm{p}}, \mathrm{Q}\right)$.

Similarly we can prove that if $f_{2}(e)=1$ then $f_{1}(e)=1$ in $\mathrm{G}\left(\mathrm{Z}_{\mathrm{p}}, \mathrm{Q}\right)$.

(ii) Suppose $f_{1}(e)=0$. Then it follows that

$$
\begin{aligned}
f_{1}(e)=0 & \Leftrightarrow \quad e \notin P_{f_{1}}^{\prime} \\
& \Leftrightarrow e \notin P_{f_{2}}^{\prime} \quad\left(\because P_{f_{1}}^{\prime}=P_{f_{2}}^{\prime}\right) \\
& \Leftrightarrow f_{2}(e)=0 .
\end{aligned}
$$

(iii) Suppose $\sum_{e^{\prime} \in N[e]} f_{1}\left(e^{\prime}\right)=1$. Then it follows that

$$
\begin{aligned}
\sum_{e^{\prime} \in N[e]} f_{1}\left(e^{\prime}\right)=1 & \Leftrightarrow e \in B_{f_{1}}^{\prime} \\
& \Leftrightarrow e \in B_{f_{2}}^{\prime} \quad\left(\because B_{f_{1}}^{\prime}=B_{f_{2}}^{\prime}\right) \\
& \Leftrightarrow \sum_{e^{\prime} \in N[e]} f_{2}\left(e^{\prime}\right)=1 .
\end{aligned}
$$

Hence the result.

Lemma 4.2: Let $f_{1}$ and $f_{2}$ be two distinct MEDFs of $\mathrm{G}\left(\mathrm{Z}_{\mathrm{p}}, \quad \mathrm{Q}\right) \quad$ with $P_{f_{1}}^{\prime}=P_{f_{2}}^{\prime} \quad$ and $\quad B_{f_{1}}^{\prime}=B_{f_{2}}^{\prime}$. Let $\alpha(e)=f_{1}(e)-f_{2}(e)$, where $e \in E$. Then (i) if $f_{1}(e)=0$ or $f_{1}(e)=1$, then $\alpha(e)=0$. (ii) $\sum_{e^{\prime} \in N[e]} \alpha\left(e^{\prime}\right)=0, \quad$ for all $e \in B_{f_{1}}^{\prime}$.

Proof: Let $f_{1}$ and $f_{2}$ be two distinct MEDFs of $\mathrm{G}\left(\mathrm{Z}_{\mathrm{p}}, \mathrm{Q}\right)$ with $P_{f_{1}}^{\prime}=P_{f_{2}}^{\prime}$ and $B_{f_{1}}^{\prime}=B_{f_{2}}^{\prime}$. Let

$\alpha(e)=f_{1}(e)-f_{2}(e)$, where $e \in E\left(G\left(Z_{p}, Q\right)\right)$.

If $f_{1}(e)=0$ then by Theorem 4.1, it follows that $f_{2}(e)=0$.

This implies that $\alpha(e)=0$.

Let $e \in B_{f_{1}}^{\prime}$. Then $e \in B_{f_{2}}^{\prime}$.

$$
\begin{aligned}
& \text { That is } \sum_{e^{\prime} \in N[e]} f_{1}\left(e^{\prime}\right)=1 \\
& \text { and } \sum_{e^{\prime} \in N[e]} f_{2}\left(e^{\prime}\right)=1 \text {. }
\end{aligned}
$$

Now

$$
\begin{aligned}
\sum_{e^{\prime} \in N[e]} \alpha\left(e^{\prime}\right) & =\sum_{e^{\prime} \in N[e]}\left[f_{1}\left(e^{\prime}\right)-f_{2}\left(e^{\prime}\right)\right] \\
& =\sum_{e^{\prime} \in N[e]} f_{1}\left(e^{\prime}\right)-\sum_{e^{\prime} \in N[e]} f_{2}\left(e^{\prime}\right) \\
& =1-1=0 .
\end{aligned}
$$

Hence the result.

Theorem 4.3: Let $f_{1}$ be a MEDF of $G\left(Z_{p}, Q\right)$. Suppose $f_{1}$ is not a BMEDF. Then there exists a MEDF $\mathrm{f}_{2}$ of $\mathrm{G}\left(\mathrm{Z}_{\mathrm{p}}, \mathrm{Q}\right)$ such that $B_{f_{1}}^{\prime}=B_{f_{2}}^{\prime}$ and $P_{f_{1}}^{\prime}=P_{f_{2}}^{\prime}$.

Proof: Let $f_{1}$ be a MEDF of $G\left(Z_{p}, Q\right)$. Suppose $f_{1}$ is not a BMEDF of $\mathrm{G}\left(\mathrm{Z}_{\mathrm{p}}, \mathrm{Q}\right)$. Then there exists MEDFs $g_{1}, g_{2}$ such that $f_{1}=\lambda_{1} g_{1}+\lambda_{2} g_{2}$, where $0<\lambda_{1}<1,0<\lambda_{2}<1$ and $\lambda_{1}+\lambda_{2}=1$. Let $f_{2}=\mu_{1} g_{1}+\mu_{2} g_{2}$,

where $0<\mu_{1}<1, \quad 0<\mu_{2}<1$ and $\mu_{1}+\mu_{2}=1$ be another convex combination of $g_{1}$ and $g_{2}$.

By Theorem 2.2 of [6] it follows that $B_{f_{1}}^{\prime}=B_{f_{2}}^{\prime}=B_{g_{1}}^{\prime} \cap B_{g_{2}}^{\prime}$ and $P_{f_{1}}^{\prime}=P_{f_{2}}^{\prime}=P_{g_{1}}^{\prime} \cup P_{g_{2}}^{\prime}$.

By Theorem 3.1, $\mathrm{f}_{1}$ is a MEDF if and only if $B_{f_{1}}^{\prime} \rightarrow P_{f_{1}}^{\prime}$. Since $B_{f_{1}}^{\prime}=B_{f_{2}}^{\prime}$ and $P_{f_{1}}^{\prime}=P_{f_{2}}^{\prime}$ it follows that $B_{f_{2}}^{\prime} \rightarrow P_{f_{2}}^{\prime}$.

Again by Theorem 3.1, $\mathrm{f}_{2}$ becomes a MEDF. Hence the Theorem. 
Theorem 4.4: Let $h$ be a MEDF of $G\left(Z_{p}, Q\right)$ with

$B_{h}^{\prime}=\left\{e_{1}, e_{2}, \ldots, e_{n}\right\}$ and

$P_{h}^{\prime}=\left\{e^{\prime} \in E / 0<h\left(e^{\prime}\right)<1\right\}=\left\{e_{1}^{\prime}, e_{2}^{\prime}, \ldots, e_{k}^{\prime}\right\}$.

Let $A=\left(a_{i j}\right)$ be an $\mathrm{n} \times \mathrm{k}$ matrix defined by

$a_{i j}=\left\{\begin{array}{l}1, \text { if } e_{i} \text { is adjacent to } e_{j}^{\prime}(\text { or }) e_{i}=e_{j}^{\prime}, \\ 0, \text { otherwise }\end{array}\right.$

Consider the system of linear equations given by

$$
\sum_{j=1}^{k} a_{i j} x_{j}=0, \text { where } 1 \leq i \leq n
$$

Then $\mathrm{h}$ is a BMEDF if and only if (1) does not have a nontrivial solution.

Proof: Let $h$ be a MEDF of $G\left(Z_{p}, Q\right)$. Suppose $h$ is not a BMEDF of $\mathrm{G}\left(\mathrm{Z}_{\mathrm{p}}, \mathrm{Q}\right)$. Then by Theorem 4.3, it follows that there exists a MEDF f such that $B_{h}^{\prime}=B_{f}^{\prime}$ and $P_{h}^{\prime}=P_{f}^{\prime}$.

Let $x_{j}=h\left(e_{j}^{\prime}\right)-f\left(e_{j}^{\prime}\right)$, where $1 \leq i \leq k$.

Suppose $x_{j}=0$ for all $\mathrm{j}=1,2, \ldots, \mathrm{k}$. The $h\left(e_{j}^{\prime}\right)=f\left(e_{j}^{\prime}\right)$ for all $e_{j}^{\prime} \in P_{h}^{\prime}$. And if $\mathrm{h}\left(e_{j}^{\prime}\right)=0$ then $e_{j}^{\prime} \notin P_{h}^{\prime}$. Since $P_{h}^{\prime}=P_{f}^{\prime}$ we get $f\left(e_{j}^{\prime}\right)=0$. Also if $\mathrm{h}\left(e_{j}^{\prime}\right)=1$ then it follows by Theorem 4.1 that $f\left(e_{j}^{\prime}\right)=1$. Thus $\mathrm{h}=\mathrm{f}$, which is a contradiction. Therefore $x_{j} \neq 0$ for atleast one $\mathrm{j}$.

Now $\sum_{j=1}^{k} a_{i j} x_{j}=\sum_{u \in N\left[e_{i}\right]} a_{i j}\left[h\left(e^{\prime}\right)-f\left(e^{\prime}\right)\right]$.
Since $e_{i} \in B_{h}^{\prime}$, it follows by Theorem 4.2 that

$$
\sum_{j=1}^{k} a_{i j} x_{j}=0, \text { where } 1 \leq i \leq n .
$$

Thus (1) has nontrivial solution.

\section{REFERENCES}

[1] Arumugam, S., and Sithara Jerry. - Fractional edge domination in graphs, Appl. Anal. Discrete Math. 3 (2009), 359-370.

[2] Arumugam, S., and Velammal, S. - Edge domination in graphs, Taiwanese Journal of Mathematics, 2 (2) (1998), 173-179.

[3] Cockayne, E. J., and Mynhardt, C. M. - Convexity of extremal domination-related functions of graphs. In Domination in Graphs - Advanced Topics, (Ed. T. W. Haynes, S. T. Hedetniemi, P. J. Slater), Marcel Dekker, Inc., New York, (1998), 109-131.

[4] Haynes, T. W., Hedetniemi, S. T., and Slater, P. J. Fundamentals of domination in graphs, Marcel Dekker, Inc., New York (1998).

[5] Haynes, T. W., Hedetniemi, S. T., and Slater, P. J. Domination in Graphs: Advanced Topics, Marcel Dekker, Inc., New York (1998).

[6] Jeelani Begum, S., Maheswari, B., Edge Dominating Functions of Quadratic Residue Cayley Graphs International Journal of Computer Applications Vol 54(17), (2012), 47-49.

[7] Mitchell, S., and Hedetniemi, S. T. - Edge domination in trees. Congr. Numer., 19 (1977), 489-509.

[8] Nathanson, Melvyn B. - Connected components of arithmetic graphs, Monat. fur. Math, 29 (1980), 219 220. 